\title{
Quantitative regional associations between remodeling, modeling, and osteocyte apoptosis and density in rabbit tibial midshafts
}

\author{
Nicole L. Hedgecock ${ }^{\mathrm{a}, \mathrm{b}}$, Tamer Hadi ${ }^{\mathrm{a}, \mathrm{b}}$, Andrew A. Chen ${ }^{\mathrm{a}, \mathrm{c}}$, Shane B. Curtiss ${ }^{\mathrm{a}}$, \\ R. Bruce Martin ${ }^{\mathrm{a}, \mathrm{b}}$, Scott J. Hazelwood ${ }^{\mathrm{a}, \mathrm{b}, *}$ \\ ${ }^{a}$ Lawrence J. Ellison Musculoskeletal Research Center, Department of Orthopaedic Surgery, University of California Davis Medical Center, \\ Sacramento, CA 95817, USA \\ ${ }^{\mathrm{b}}$ Biomedical Engineering Graduate Group, University of California, Davis, CA 95616, USA \\ ${ }^{\mathrm{c}}$ Department of Biological and Agricultural Engineering, University of California, Davis, CA 95616, USA
}

\begin{abstract}
Evidence suggests that osteocyte apoptosis is involved in the adaptive response of bone, although the specific role of osteocytes in the signaling mechanism is unknown. Here, we examined and correlated regional variability in indices of remodeling, modeling, osteocyte apoptosis, and osteocyte density in rabbit tibia midshafts. Histomorphometric analysis indicated that remodeling parameters (BMU activation frequency, osteon density, forming osteon density, and resorption cavity density) were lower in the cranial region compared to other quadrants. In addition, pericortical subregions displayed less remodeling relative to intracortical and endocortical ones. Modeling indices also demonstrated regional variability in that periosteal surfaces exhibited a greater extent of bone forming surface than endosteal ones across all anatomic quadrants. In contrast, endosteal surfaces demonstrated significantly greater surface mineral apposition rates compared to periosteal surfaces in caudal, medial, and lateral but not cranial quadrants. Using TUNEL analysis to detect osteocytes undergoing apoptosis, the density of apoptotic osteocytes was found to be lower in cranial quadrants relative to medial ones. In addition, the densities of osteocyte lacunae, empty lacunae, and total osteocytes were higher in lateral fields relative to caudal quadrants. There was a strong, statistically significant linear correlation between the remodeling indices and apoptotic osteocyte density, supporting the theory that osteocytes undergoing apoptosis produce signals that attract or direct bone remodeling. In contrast, the modeling parameters did not exhibit a correlation with apoptotic osteocytes, although there was a strong correlation between the modeling indices and the density of empty osteocyte lacunae, corroborating previous studies that have found that osteocytes inhibit bone formation. It was found that osteocyte density and osteocyte lacunar density did not significantly correlate with modeling or remodeling parameters, suggesting that cell viability should be examined in studies correlating bone turnover parameters with the functional role of osteocytes in bone adaptation.
\end{abstract}

Keywords: Modeling; Remodeling; Osteocyte apoptosis; TUNEL; Rabbit tibiae

\section{Introduction}

It has been previously suggested that osteocytes, differentiated osteoblasts embedded in bone matrix, play a central role in the maintenance and integrity of bone $[45,52,64,74]$.
They are the most abundant of bone cells and are connected through their dendritic processes and gap junctions to one another, osteoblasts, and lining cells in a syncytium that is ideally dispersed to both sense local mechanical environments and participate in the signaling mechanism that initiates and guides bone turnover $[18,37,51,56,57,84,98]$. The precise role of the osteocyte network in this signaling, however, remains controversial in three respects.

First, the function of the osteocyte network, and specifically whether it is primarily metabolic or mechanical, remains in question. Early work suggested a critical role for osteocytes in 
mineral exchange and homeostasis through a process of osteolysis $[3,77]$. However, this theory has been largely refuted and supplanted by evidence that osteocytes act as skeletal mechanosensors and transducers [10,14,20,45,46,80,92]. Nevertheless, recent work notes that osteocytes possess receptors for parathyroid hormone [15], a regulator of mineral ion homeostasis, and can modify their microenvironments through localized leaching of mineral [44], suggesting a multifunctional role for the network.

A second unknown in osteocyte physiology is the nature of the signals to which these cells respond. Candidate signaling mechanisms include the direct sensation of strain $[14,33,39,60,61]$ potentially through stretch-activated ion channels [19], fluid flow-induced shear stress or streaming potentials $[11,34,65,83,95,99,100]$, the interruption of normal cellular communication and metabolism by microdamage $[5,12,59]$, and oxygen deprivation $[17,27,29]$.

Finally, once the osteocyte network senses a stimulatory signal, its role in eliciting an adaptive response remains unclear [7]. One hypothesis states that the osteocyte network mediates strain-related mechanical adaptation through modeling and remodeling processes $[2,20,30,39,45,46,80,84]$. In this theory, the osteocyte network controls tissue architecture to maintain strains within genetically programmed and physiologically prescribed limits. A second hypothesis proposes that viable osteocytes send inhibitory signals that prevent bone lining cells from initiating a basal remodeling response [51,52]. Disruptions of the network exceeding a critical threshold, caused, for example, by microdamage, would permit and direct a remodeling response. A third theory postulates that damaged or dying osteocytes secrete a signal that initiates and guides osteoclastic resorption of bone $[5,10,11,63,67,92]$.

It has been known for over a decade that osteocytes undergo in vivo DNA fragmentation characteristic of programmed cell death, or apoptosis, in developing and pathologic bone $[9,63]$. Noble et al. [63] found a non-uniform distribution of apoptotic osteocytes among the femoral head, iliac crest, and calvaria, raising the possibility of a functional relationship between programmed osteocyte death and bone turnover. More recent work has correlated osteocyte apoptosis with bone remodeling after the imposition of fatigue or supraphysiologic loading regimens $[5,62,92,93]$. To date, the latter studies have provided the strongest evidence of temporal and spatial relationships between osteocyte apoptosis and bone remodeling.

Complex loading patterns on long bones offer a unique opportunity to examine the effects of regional variations in bone's mechanical environment on modeling and remodeling. Torrance et al. [90] found a correlation between periosteal bone formation and the longitudinal strain magnitude around the circumference of cyclically loaded rat ulnae. Gross and colleagues [28] demonstrated a strong spatial correlation between strain gradients and periosteal bone formation in exogenously loaded adult turkey radii. Judex and co-workers [38] corroborated this result, finding a strong spatial correlation between induced peak circumferential strain gradient and periosteal bone formation in adult rooster mid-diaphyseal tarsometatarsals. Noble et al. [62] found regional differences in formation and resorption on bone surfaces, as well as variability in the circumferential distribution of osteocytes undergoing apoptosis, in normally loaded rat ulna cortices. While other studies have confirmed regional heterogeneity in modeling, remodeling, and tissue architecture across several species $[23,26,35,54,78,79]$, to our knowledge, no one has yet quantified regional variability in indices of bone turnover and osteocyte apoptosis and correlated them in a single report. The present study aims to meet this need by quantifying and correlating regional variability in indices of bone remodeling and modeling, and osteocyte apoptosis and density, in transverse sections of the rabbit tibial midshaft. We hypothesize that regional variations in remodeling and modeling indices will correlate with osteocyte apoptosis.

\section{Materials and methods}

Eight male, skeletally mature, New Zealand white rabbits (3.0-3.5 kg) were procured (Charles River Laboratories, Wilmington, MA) and given 1 week to acclimate to their surroundings. For the duration of the study, each animal was allowed unrestricted movement in a $0.9 \mathrm{~m} \times 0.6 \mathrm{~m} \times 0.5 \mathrm{~m}$ cage and given food and water ad libitum. To label newly mineralized bone, each animal was injected with $10 \mathrm{mg} / \mathrm{kg}$ of calcein green (Sigma, St. Louis, MO) 10 and 3 days prior to sacrifice. At necropsy, both tibiae were manually dissected free of soft tissues. Right tibiae were processed immediately for assessment of osteocyte viability, while left tibiae were stored in $70 \% \mathrm{EtOH}$ for undecalcified histomorphometry. Procedures were conducted with approval from the Institutional Animal Care and Use Committee at UC Davis.

\section{Histomorphometry: modeling and remodeling}

After storage in $70 \% \mathrm{EtOH}$, the proximal and distal epiphyses of all left tibiae were removed using a high-speed diamond saw (Gillings-Hamco, Rochester, NY). Remaining midshafts were stained en bloc in basic fuchsin and then embedded in methyl methacrylate [13]. Thirty $200 \mu \mathrm{m}$ thick sections were cut from each midshaft distal to the tibio-fibular junction, then handground to a thickness of $100 \mu \mathrm{m}$ using a series of silicon carbide abrasive papers with increasingly fine grit (Buelher, Inc., Lake Bluff, IL). From these thirty sections, five sections spaced $2-3 \mathrm{~mm}$ apart were used for modeling and remodeling histomorphometry.

Both modeling and remodeling histomorphometry were performed at $125 \times$ magnification on a light microscope. To facilitate the analysis, each of the five

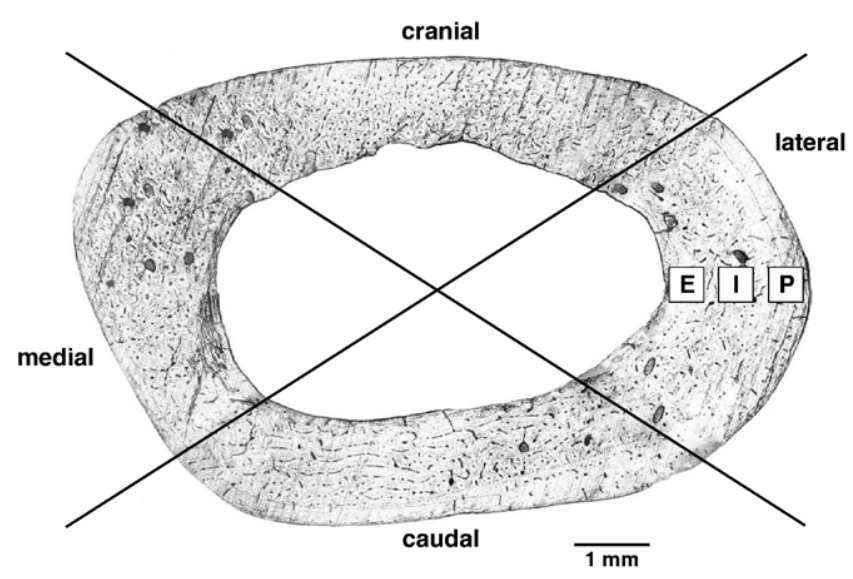

Fig. 1. Photomicrograph of undecalcified cortex of rabbit tibia at the middiaphysis. The transverse cross-section shows approximate locations of the anatomic quadrants and radial subregions - endocortical (E), intracortical (I), and pericortical $(\mathrm{P})$ - from which histomorphometric data were collected. 
sections was divided into four anatomic quadrants: cranial (anterior), cauda (posterior), medial, and lateral (Fig. 1). Each quadrant was further divided into three radial subregions: pericortical, intracortical, and endocortical. Total endosteal and periosteal perimeters and labeled surfaces of each region were measured using ImageJ (U.S. National Institutes of Health).

Modeling was quantified by bone forming surface (L.Pm/B.Pm), the amount of fluorescent-labeled bone surface length relative to total periosteal or endosteal surface lengths; surface mineral apposition rate (surface MAR); and their product, bone formation rate (BFR/BS). To estimate mineral apposition rates, interlabel distances were measured using Image $J(0.5 \mu \mathrm{m} /$ pixel $)$ from the center of one label to the center of the second and divided by the interlabel administration time of 7 days [40]. For both periosteal and endosteal surfaces, measurements were made every $150 \mu \mathrm{m}$ along double labeled surfaces for an average of 13 measurements per subregion.

Remodeling was quantified by both static and dynamic parameters counted in each field. Each numerical count was converted to a density by normalizing by tissue area, which was assessed by point counting using a 36-point Merz grid. Static parameters included resorption cavity density (Rs.Dn, voids larger than Haversian canals with scalloped edges), forming basic multicellular unit (BMU) density (FOn.Dn, characterized by a cement line and single or double calcein label), and secondary osteon density (On.Dn, identified by the absence of fluorescent labeling, the presence of a single Haversian canal, and a unique cement line per osteon). To correct for label escape error, forming osteon number was calculated as the sum of the number of double-labeled osteons and half of the number of single-labeled osteons [25]. Additionally, for three secondary osteons in three sections per subject, the diameters of the cement line and Haversian canal were measured along two orthogonal directions at $250 \times$ magnification and averaged in each anatomical quadrant. Wall width (W.Wi) for each osteon was calculated as the difference between its cement line and Haversian canal radii. Intracortical porosity (Po), the percentage of void space in bone, including resorption cavities and Haversian and Volkmann's canals, but excluding osteocyte lacunae and canaliculi, was measured by point counting using a 121-point square grid at $125 \times$ magnification.

Dynamic remodeling parameters were measured on the same five sections used for static modeling and remodeling parameters. These included intracortical mineral apposition rate (Ia.Ct.MAR), which was averaged over four measurements per refilling osteon; formation period (FP), calculated as average osteonal W.Wi divided by Ia.Ct.MAR; and activation frequency (Ac.f), defined as forming osteon density divided by formation period.

\section{TUNEL staining and osteocyte apoptosis}

Following sacrifice, a $5 \mathrm{~mm}$ segment of diaphyseal cortex was removed from each right tibia distal to the tibiofibular junction using a high-speed diamond saw (Gillings-Hamco, Rochester, NY). Tissue fixation, decalcification, and processing followed previously published methods $[50,81,92]$. Each block was fixed in $4 \%$ paraformaldehyde at $4^{\circ} \mathrm{C}$ for $24 \mathrm{~h}$ then decalcified in $15 \%$ disodium EDTA (Fisher Chemical, Fairlawn, NJ) at room temperature under constant agitation for 4 to 6 weeks. The EDTA solution was changed every 12 days, and decalcification was monitored radiographically [81]. When decalcification was complete, the bones were infiltrated and embedded in paraffin. Sections $6 \mu \mathrm{m}$ thick were cut from each bone block and adhered to positively charged slides. From each subject, three wrinkle-free sections were stained using TUNEL (Terminal deoxynucleotidyl transferase (TdT)-mediated deoxyuridine triphosphate nick-end labeling) to identify cellular DNA fragmentation characteristic of apoptosis

The DeadEnd Colorimetric System (Promega Corp., Madison, WI) was used for the TUNEL studies. Paraffin sections were dewaxed, rehydrated by a graded alcohol series, and refixed in $10 \%$ neutral buffered formalin. Sections were digested with $20 \mu \mathrm{g} / \mathrm{mL}$ proteinase $\mathrm{K}$ for $10 \mathrm{~min}$ at room temperature. After equilibration, $100 \mu \mathrm{L}$ of the TUNEL reaction mixture (1 part biotinylated nucleotides, 1 part rTdT enzyme, and 98 parts buffer) was added to each section and allowed to incubate $\left(1 \mathrm{~h}\right.$, in a humidifying chamber at $\left.37^{\circ} \mathrm{C}\right)$. The reaction was then stopped with an SSC wash, and the sections were treated with $0.3 \%$ $\mathrm{H}_{2} \mathrm{O}_{2}$ for 5 min to block endogenous peroxidases. After PBS rinses, the slides were treated with streptavidin horseradish peroxidase for $30 \mathrm{~min}$ then developed with $\mathrm{DAB}$ substrate for visualization of the peroxidase. All sections were counterstained with $0.1 \%$ methyl green (Aldrich Chemical Co., St. Louis, MO) to reveal nuclei, mounted with Permount (Fisher Chemical, Fairlawn, NJ), and coverslipped. Sections with DNA breaks artificially created by deoxyribonuclease (RQ1 RNase-free DNase, Promega Corp., Madison, WI) treatment served as positive controls for TUNEL, while slides to which no rTdT enzyme had been added to the reaction mixture served as negative controls. To prevent contamination, all positive controls were placed in a single staining set separate from non-positive controls.

To quantify osteocyte apoptosis, images of the cortical areas were captured in each anatomic quadrant (cranial, caudal, medial, and lateral) at $250 \times$ $(0.4 \mu \mathrm{m} / \mathrm{pixel})$ via light microscope. Each quadrant was further divided into subregions corresponding to pericortical, intracortical, and endocortical areas. For each specimen, five fields per subregion per quadrant were randomly selected for blinded analysis with ImageTool (UTHSCSA Dental Diagnostic Science). Osteocyte lacunae, characterized by distinct lacunar walls, were sorted into one of three categories based on the absence or presence and staining pattern of their respective osteocyte nuclei: (1) TUNEL-positive, (2) TUNEL-negative, and (3) empty. Cells were examined for nuclear blebbing and chromatin condensation, morphological changes characteristic of apoptosis. The frequency of osteocyte apoptosis was expressed both as a percentage of total cells in the region of interest and as a density (number per unit tissue area).

\section{Statistical analysis}

Regional variability of measured and calculated histomorphometric parameters, osteocyte apoptosis, and osteocyte density was determined via ANOVA blocked by subject. To clarify regional trends, data were pooled in three ways: by anatomic quadrant, by radial subregion, and by both quadrant and subregion. The criterion for statistical significance was $p<0.05$. Post hoc analysis was performed using the Tukey-Kramer test. Correlation and regression analyses were also performed to study the relationships between modeling, remodeling, osteocyte apoptosis, and osteocyte density.

Table 1

Remodeling indices (mean \pm SD) in mid-diaphyseal cortices of rabbit tibiae $(n=8)$

\begin{tabular}{|c|c|c|c|c|c|}
\hline & On.Dn (\#/mm²) & FOn.Dn $\left(\# / \mathrm{mm}^{2}\right)$ & Rs.Dn (\#/mm²) & FP (day) & Ac.f (BMUs $/ \mathrm{mm}^{2} /$ year) \\
\hline Overall & $2.32 \pm 3.03$ & $1.04 \pm 1.24$ & $0.36 \pm 0.41$ & $25.4 \pm 8.0$ & $11.6 \pm 13.7$ \\
\hline \multicolumn{6}{|l|}{ Quadrant } \\
\hline Caudal & $3.52 \pm 3.10^{\mathrm{a}}$ & $1.38 \pm 1.21^{\mathrm{a}, \mathrm{c}}$ & $0.47 \pm 0.47^{\mathrm{a}, \mathrm{c}}$ & $26.5 \pm 9.5$ & $16.1 \pm 13.8^{\mathrm{a}}$ \\
\hline Cranial & $0.19 \pm 0.41^{b}$ & $0.22 \pm 0.37^{b}$ & $0.18 \pm 0.26^{\mathrm{b}}$ & $26.0 \pm 9.1$ & $1.7 \pm 3.5^{\mathrm{b}}$ \\
\hline Lateral & $2.46 \pm 3.20^{\mathrm{a}}$ & $0.94 \pm 1.04^{\mathrm{a}}$ & $0.30 \pm 0.28^{\mathrm{a}, \mathrm{b}}$ & $24.7 \pm 7.4$ & $11.4 \pm 13.5^{\mathrm{a}}$ \\
\hline Medial & $3.13 \pm 3.24^{\mathrm{a}}$ & $1.63 \pm 1.54^{\mathrm{c}}$ & $0.51 \pm 0.50^{\mathrm{c}}$ & $24.8 \pm 6.5$ & $17.2 \pm 14.9^{\mathrm{a}}$ \\
\hline \multicolumn{6}{|l|}{ Subregion } \\
\hline Endocortical & $3.05 \pm 2.92^{\mathrm{a}}$ & $1.48 \pm 1.36^{\mathrm{a}}$ & $0.69 \pm 0.69^{\mathrm{a}}$ & $18.3 \pm 4.5^{\mathrm{a}}$ & $25.2 \pm 21.8^{\mathrm{a}}$ \\
\hline Intracortical & $3.79 \pm 3.57^{\mathrm{a}}$ & $1.70 \pm 1.72^{\mathrm{a}}$ & $0.50 \pm 0.48^{\mathrm{a}}$ & $24.1 \pm 6.3^{\mathrm{a}}$ & $18.6 \pm 17.4^{\mathrm{a}}$ \\
\hline Pericortical & $1.07 \pm 1.27^{\mathrm{b}}$ & $0.46 \pm 0.53^{b}$ & $0.13 \pm 0.19^{\mathrm{b}}$ & $34.1 \pm 13.9^{b}$ & $4.2 \pm 5.8^{b}$ \\
\hline
\end{tabular}

a,b,c Dissimilar characters indicate a significant difference with $p<0.05$. 


\section{Results}

\section{Regional variability}

BMU activation frequency (Ac.f) was significantly lower in cranial fields than other anatomic quadrants (Table 1). Similarly, densities of secondary osteons (On.Dn) and forming osteons (FOn.Dn) were significantly lower in cranial quadrants, while FOn.Dn was also higher in medial fields relative to lateral ones. Likewise, the cranial quadrant exhibited a lower resorption cavity density (Rs.Dn) compared with caudal and medial fields, and medial quadrants demonstrated greater Rs.Dn than lateral ones. Pericortical fields displayed significantly lower levels of remodeling as measured by Ac.f, FOn.Dn, On.Dn, and Rs.Dn relative to intracortical and endocortical fields (Table 1). Formation period (FP) was significantly higher in the pericortex compared with intracortical and endocortical subregions. Porosity (Po, overall mean 3.22 $\pm 0.97 \%$ ), ranged from $2.99 \pm$ $0.99 \%$ in cranial quadrants to $3.49 \pm 1.01 \%$ in caudal ones, and did not exhibit significant differences between quadrants. Pooling data by both anatomic quadrant and radial subregion confirmed that indices of remodeling were elevated in endocortical and intracortical subregions (Fig. 2).

Modeling indices also demonstrated regional variability in that periosteal surfaces exhibited a significantly greater extent
Table 2

Modeling indices (mean $\pm \mathrm{SD})$ in mid-diaphyseal cortices of rabbit tibiae $(n=8)$

\begin{tabular}{llll}
\hline Quadrant & $\begin{array}{l}\text { L.Pm/B.Pm } \\
(\mu \mathrm{m} / \mu \mathrm{m})\end{array}$ & $\begin{array}{l}\text { Surface MAR } \\
(\mu \mathrm{m} / \text { day })\end{array}$ & $\begin{array}{l}\text { BFR/BS } \\
\left(\mu \mathrm{m}^{2} / \text { day } / \mu \mathrm{m}\right)\end{array}$ \\
\hline Caudal & & & \\
$\quad$ Endosteal & $0.19 \pm 0.31$ & $3.32 \pm 0.44^{\mathrm{b}}$ & $0.71 \pm 1.27$ \\
$\quad \begin{array}{l}\text { Periosteal } \\
\text { Cranial }\end{array}$ & $0.47 \pm 0.24^{\mathrm{c}}$ & $1.64 \pm 0.49$ & $0.90 \pm 0.59$ \\
$\quad \begin{array}{l}\text { Endosteal } \\
\text { Periosteal }\end{array}$ & $0.28 \pm 0.31$ & $2.51 \pm 0.51$ & $0.92 \pm 0.97$ \\
Lateral & $0.45 \pm 0.29^{\mathrm{b}}$ & $1.86 \pm 0.56$ & $1.28 \pm 0.88$ \\
$\quad$ Endosteal & $0.35 \pm 0.25$ & $2.99 \pm 0.64^{\mathrm{c}}$ & $1.49 \pm 0.92$ \\
Periosteal & $0.58 \pm 0.29^{\mathrm{c}}$ & $1.75 \pm 0.42$ & $1.33 \pm 0.64$ \\
Medial & & & $0.77 \pm 0.75$ \\
Endosteal & $0.27 \pm 0.22$ & $2.54 \pm 0.80^{\mathrm{b}}$ & $0.69 \pm 0.48$ \\
Periosteal & $0.41 \pm 0.24^{\mathrm{b}}$ & $1.51 \pm 0.33$ & \\
\hline
\end{tabular}

Superscripts indicate a significantly greater value within quadrants as follows: ${ }^{\mathrm{a}} p<0.05,{ }^{\mathrm{b}} p<0.01,{ }^{\mathrm{c}} p<0.001$, all others $p>0.05$.

of active mineralization (L.Pm/B.Pm) than endosteal surfaces across all anatomic quadrants (Table 2). In contrast, endosteal surfaces demonstrated significantly greater surface mineral apposition rates (surface MAR) compared to periosteal surfaces in caudal, medial, and lateral but not cranial quadrants. As such, no statistically significant evidence of variability in bone formation rate (BFR/BS) was found within quadrants (Table 2).
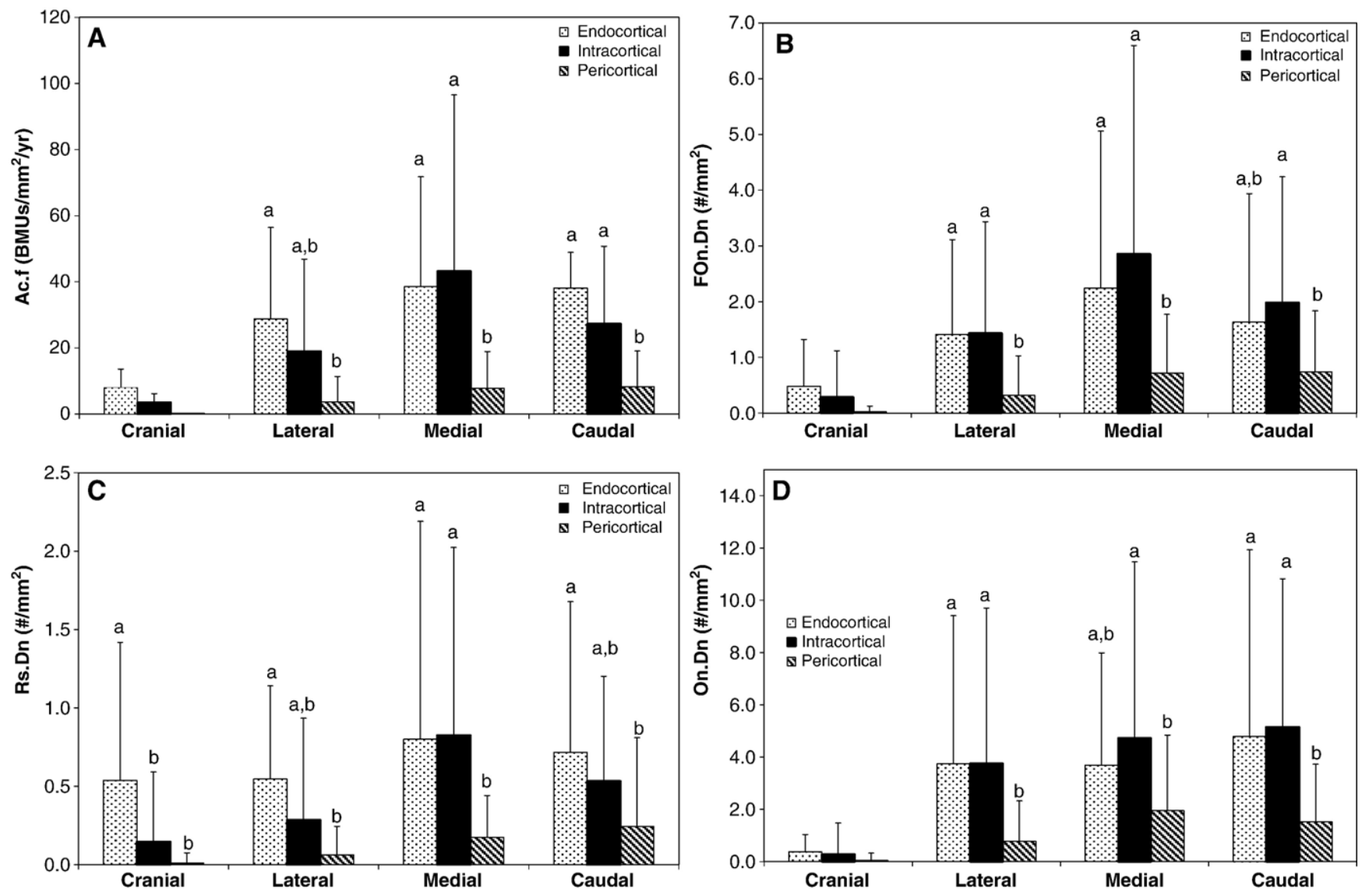

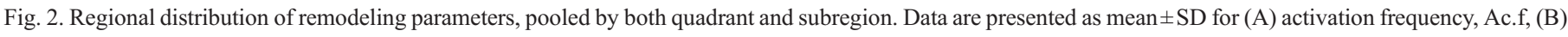

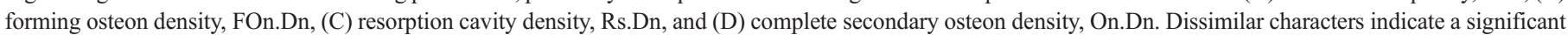
difference with $p<0.05$. 
Table 3

Osteocyte density and viability $($ mean $\pm \mathrm{SD})$ in mid-diaphyseal cortices of rabbit tibiae $(n=8)$

\begin{tabular}{|c|c|c|c|c|c|}
\hline & $\begin{array}{l}\text { Density, osteocyte lacunae } \\
\left(\# / \mathrm{mm}^{2}\right)\end{array}$ & $\begin{array}{l}\text { Density, empty lacunae } \\
\left(\# / \mathrm{mm}^{2}\right)\end{array}$ & $\begin{array}{l}\text { Density, osteocyte nuclei } \\
\left(\# / \mathrm{mm}^{2}\right)\end{array}$ & $\begin{array}{l}\text { Density, apoptotic osteocytes } \\
\left(\# / \mathrm{mm}^{2}\right)\end{array}$ & $\begin{array}{l}\text { Percentage, apoptotic } \\
\text { osteocytes }(\%)\end{array}$ \\
\hline Overall & $694.5 \pm 42.1$ & $148.9 \pm 19.4$ & $545.6 \pm 38.0$ & $48.0 \pm 40.3$ & $9.1 \pm 8.3$ \\
\hline \multicolumn{6}{|l|}{ Quadrant } \\
\hline Caudal & $661.8 \pm 45.2^{\mathrm{a}}$ & $132.6 \pm 22.2^{\mathrm{a}}$ & $529.1 \pm 40.9^{\mathrm{a}}$ & $49.9 \pm 50.5^{\mathrm{a}, \mathrm{b}}$ & $9.6 \pm 9.8^{\mathrm{a}, \mathrm{b}}$ \\
\hline Cranial & $691.8 \pm 66.1^{\mathrm{a}}$ & $154.9 \pm 36.6^{\mathrm{a}, \mathrm{b}}$ & $536.9 \pm 62.9^{\mathrm{a}, \mathrm{b}}$ & $27.0 \pm 21.1^{\mathrm{a}}$ & $5.4 \pm 4.9^{\mathrm{a}}$ \\
\hline Lateral & $748.9 \pm 48.5^{\mathrm{b}}$ & $164.6 \pm 24.7^{b}$ & $584.3 \pm 37.1^{\mathrm{b}}$ & $56.0 \pm 55.8^{\mathrm{a}, \mathrm{b}}$ & $9.8 \pm 10.3^{\mathrm{a}, \mathrm{b}}$ \\
\hline Medial & $675.5 \pm 47.5^{\mathrm{a}}$ & $143.6 \pm 21.5^{\mathrm{a}, \mathrm{b}}$ & $531.9 \pm 49.0^{\mathrm{a}}$ & $59.0 \pm 46.4^{b}$ & $11.6 \pm 10.0^{\mathrm{b}}$ \\
\hline \multicolumn{6}{|l|}{ Subregion } \\
\hline Endocortical & $679.3 \pm 41.8$ & $128.8 \pm 20.7^{\mathrm{a}}$ & $550.5 \pm 28.0$ & $54.5 \pm 72.1$ & $9.8 \pm 13.0$ \\
\hline Intracortical & $690.8 \pm 53.7$ & $134.1 \pm 29.0^{\mathrm{a}}$ & $556.7 \pm 31.0$ & $55.4 \pm 42.5$ & $10.2 \pm 8.4$ \\
\hline Pericortical & $709.1 \pm 77.7$ & $183.1 \pm 47.5^{\mathrm{b}}$ & $526.1 \pm 90.8$ & $31.4 \pm 16.9$ & $6.2 \pm 3.7$ \\
\hline
\end{tabular}

${ }^{\mathrm{a}, \mathrm{b}}$ Dissimilar characters indicate a significant difference with $p<0.05$.

However, there were instances of variability in modeling parameters between quadrants. Most notably, periosteal L.Pm/ B.Pm and periosteal BFR/BS were significantly greater in lateral quadrants relative to medial ones (Table 2, $p=0.0078$ and $p=0.0006$, respectively). Bone formation rates on periosteal surfaces in cranial quadrants were also significantly greater than those on medial quadrants (Table 2, $p=0.004$ ).

In terms of the distribution of osteocytes, lateral fields were characterized by statistically higher areal densities of total lacunae (Lc.Dn), empty lacunae (e.Lc.Dn), and osteocytes (Ot. Dn) relative to caudal fields; greater Lc.Dn than cranial and medial fields; and higher Ot.Dn than medial ones (Table 3). In contrast, densities (Ap.Ot.Dn) and percentages of apoptotic osteocytes were significantly lower in cranial quadrants relative to medial quadrants. Endocortical and intracortical subregions were characterized by significantly lower densities of empty lacunae compared to pericortical ones (Table 3).

\section{Regressions and general correlations}

There was a strong, statistically significant linear correlation between BMU activation frequency (Ac.f) and apoptotic osteocyte density (Ap.Ot.Dn, Fig. 3). Similarly, densities of secondary osteons (On.Dn), forming osteons (FOn.Dn), and

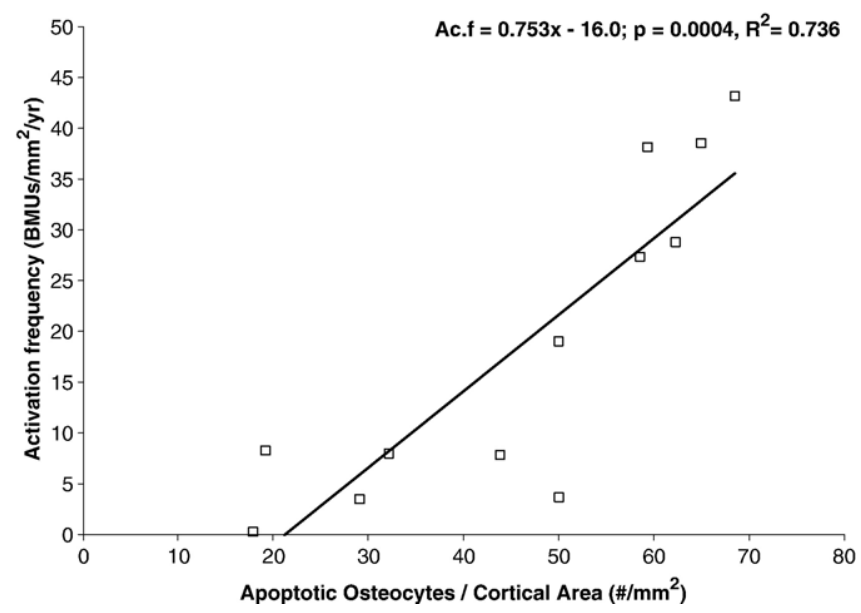

Fig. 3. Basic multicellular unit activation frequency (Ac.f) correlated linearly with apoptotic osteocyte density (Ap.Ot.Dn). resorption cavities (Rs.Dn) were also significantly correlated with osteocyte apoptosis (Fig. 4). When these remodeling parameters were regressed against both Ap.Ot.Dn and empty lacunar density (e.Lc.Dn), both the statistical significance and strength of the linear correlations improved (Table 4). While the relationships between Ap.Ot.Dn and the remodeling indices were positive, e.Lc.Dn was negatively correlated with these parameters (Tables 4 and 5). These relationships held true if the independent variables, osteocyte apoptosis and empty lacunae, were expressed as areal densities or as percentages of total osteocytes (Ap.Ot.N/Ot.N) and lacunae (e.Lc.N/Lc.N) in those fields (Table 4).

Remodeling parameters On.Dn, FOn.Dn, Rs.Dn, and Ac.f were all strongly mutually correlated, as expected (Table 5). Additionally, Rs.Dn and Ac.f were positively correlated with surface mineral apposition rate (surface MAR) and negatively correlated with forming surface (L.Pm/B.Pm). Porosity (Po) was negatively correlated with both bone formation rate (BFR/ BS) and wall width (W.Wi). In contrast, intracortical mineral apposition rate (Ia.Ct.MAR) was not linearly correlated with any of the parameters measured in the present study (Table 5).

The density of empty lacunae (e.Lc.Dn) was found to be strongly correlated with indices of modeling; that is, e.Lc.Dn

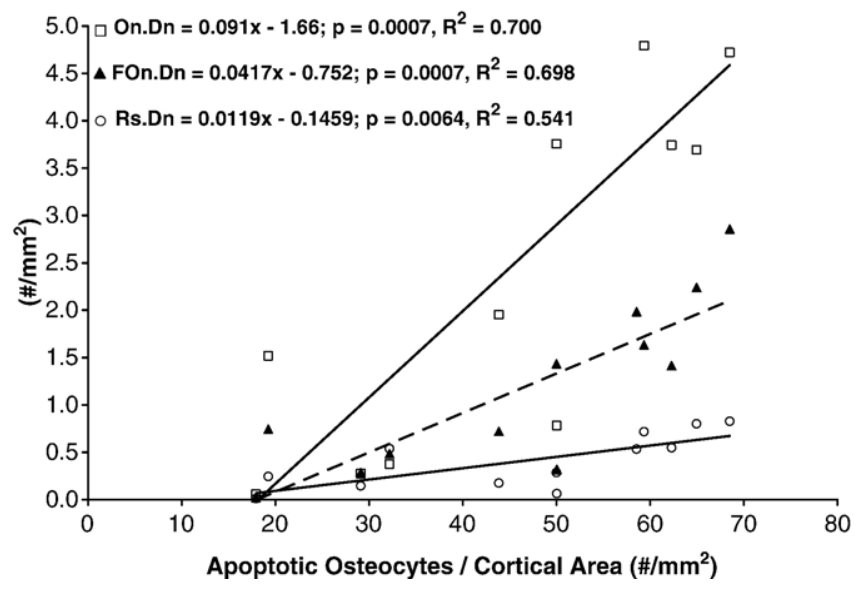

Fig. 4. Densities of complete secondary osteons (On.Dn), forming osteons (FOn.Dn), and resorption cavities (Rs.Dn) each correlated linearly with apoptotic osteocyte density (Ap.Ot.Dn). 
Table 4

Multiple linear regressions for remodeling parameters

\begin{tabular}{|c|c|c|c|c|c|}
\hline$x 1$ & $x 2$ & $y$ & Regression & $R^{2}$ & $p$-value \\
\hline Ap.Ot.Dn (\#/mm²) & e.Lc.Dn $\left(\# / \mathrm{mm}^{2}\right)$ & $\begin{array}{l}\text { Secondary osteon density, } \# / \mathrm{mm}^{2} \\
\text { Forming osteon density, } \# / \mathrm{mm}^{2} \\
\text { Resorption space density, } \# / \mathrm{mm}^{2} \\
\text { Activation frequency, BMUs } / \mathrm{mm}^{2} / \text { year }\end{array}$ & $\begin{array}{l}\text { On.Dn }=0.076 * x 1-0.025 * x 2+0.08 \\
\text { FOn.Dn }=0.035 * x 1-0.011 * x 2+0.03 \\
\text { Rs.Dn }=0.009 * x 1-0.005 * x 2+0.01 \\
\text { Ac.f }=0.615 * x 1-0.221 * x 2+0.62\end{array}$ & $\begin{array}{l}0.824 \\
0.810 \\
0.810 \\
0.887\end{array}$ & $\begin{array}{l}0.0004 \\
0.0006 \\
0.0006 \\
0.0001\end{array}$ \\
\hline$\frac{\text { Ap.Ot.N, \# }}{\text { Ot.N, \# }}$ & $\frac{\text { e.Lc.N, \# }}{\text { Lc.N, \# }}$ & $\begin{array}{l}\text { Secondary osteon density, } \# / \mathrm{mm}^{2} \\
\text { Forming osteon density, } \# / \mathrm{mm}^{2} \\
\text { Resorption space density, } \# / \mathrm{mm}^{2} \\
\text { Activation frequency, BMUs } / \mathrm{mm}^{2} / \text { year }\end{array}$ & $\begin{array}{l}\text { On.Dn }=0.434 * x 1-0.143 * x 2+0.43 \\
\text { FOn. } D n=0.215 * x 1-0.046 * x 2+0.22 \\
\text { Rs. Dn }=0.048 * x 1-0.038 * x 2+0.05 \\
\text { Ac.f }=3.799 * x 1-1.042 * x 2+3.8\end{array}$ & $\begin{array}{l}0.786 \\
0.796 \\
0.761 \\
0.866\end{array}$ & $\begin{array}{l}0.0010 \\
0.0008 \\
0.0016 \\
0.0001\end{array}$ \\
\hline
\end{tabular}

correlated positively with L.Pm/B.Pm and negatively with surface MAR (Tables 5 and 6). In contrast, there was a lack of correlation between the modeling parameters and Ap.Ot.Dn. L.Pm/B.Pm and surface MAR were negatively correlated with one another, while their product, BFR/BS, was weakly correlated only with Po in a negative relationship. There were strong, statistically significant linear correlations between Lc.Dn, Ot.Dn, and total osteocytes that did not stain positively for apoptosis via the TUNEL assay (T(-).Ot.Dn, an approximation of viable osteocytes), as expected (Table 5). None of these variables (Lc.Dn, Ot.Dn, T(-).Ot.Dn) were found to be linearly correlated with any remodeling or modeling parameters (Table 5).

\section{Discussion}

Current theories postulate that the osteocyte lacunarcanalicular network plays a critical role in skeletal mechanotransduction $[5,10,11,14,20,45,46,52,63,80,92]$. It is believed that osteocytes produce one or more signals that mediate skeletal modeling and/or remodeling in a dose-dependent manner, such that the number of osteocytes or strength of their response plays an important explanatory role in these processes. In the present study, we measured regional variability in indices of bone turnover, osteocyte density, and osteocyte apoptosis in the rabbit tibial midshaft and explored quantitative associations between them. We hypothesized that variations in remodeling and modeling parameters would correlate with regional differences in osteocyte apoptosis. Experimentally, all animals demonstrated evidence of intracortical remodeling, surface modeling, and osteocyte apoptosis under conditions of normal cage activity. While regional analysis demonstrated a strong linear correlation between osteocyte apoptosis and the remodeling parameters, a similar correlation between the modeling indices and apoptotic osteocytes was not observed. To our knowledge, this represents the first quantitative evidence that osteocyte apoptosis is spatially correlated with remodeling

Table 5

Pearson correlation coefficients $(R)$ between indices of osteocyte density and apoptosis, modeling, and remodeling for all data pooled by the combination of quadrant and subregion

$$
\begin{array}{lllllllllll}
\text { Lc.Dn } & \text { e.Lc.Dn } & \text { Ot.Dn } & \text { Ap.Ot.Dn } & \text { T(-).Ot.Dn } & \text { L.Pm/B.Pm } & \text { Surface } & \text { BFR/BS } & \text { Ia.Ct.MAR Po } & \text { W.Wi } & \text { On.Dn FOn.Dn Rs.Dn Ac.f }
\end{array}
$$
MAR

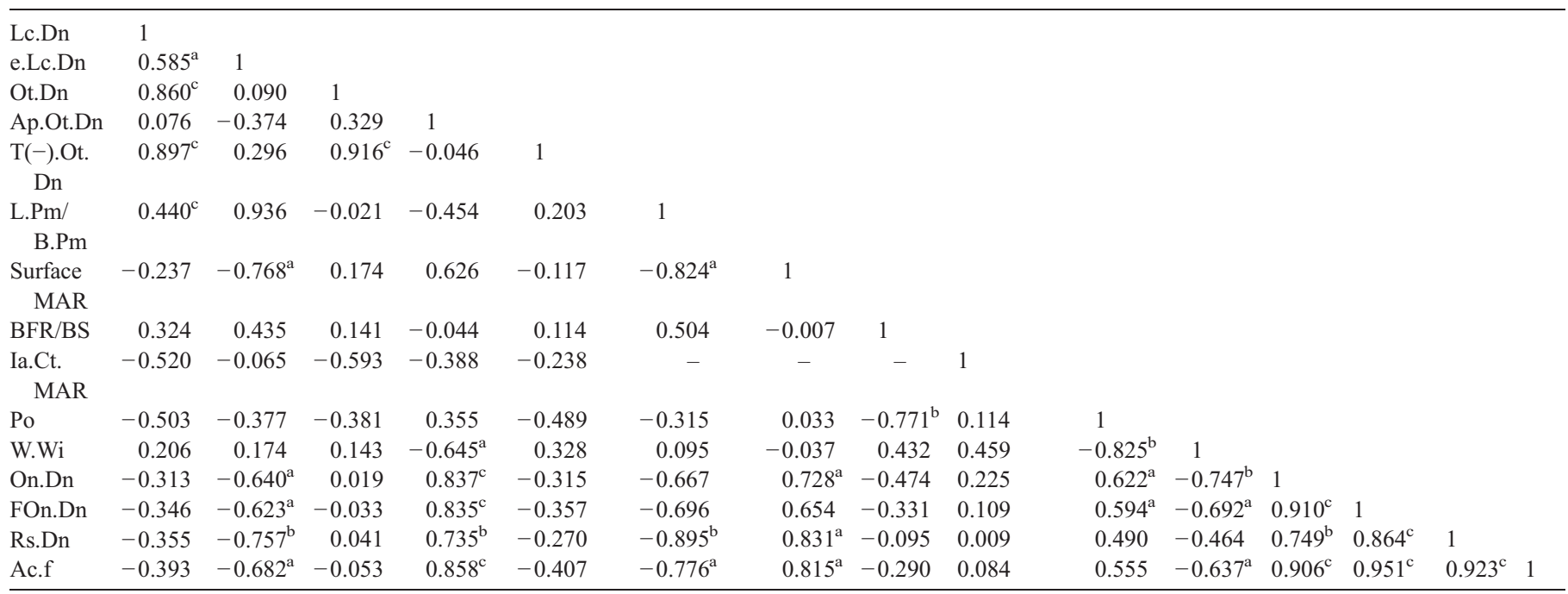

${ }^{\mathrm{a}} p<0.05,{ }_{p}^{\mathrm{b}}<0.01,{ }_{p}^{\mathrm{c}}<0.001$, all other correlations: $p>0.05$.

Abbreviations: $\mathrm{Dn}=$ density, parameter number normalized by bone area; $\mathrm{BS}=$ bone surface, $\mathrm{Lc}=$ osteocyte lacunae; $\mathrm{e} . \mathrm{Lc}=\mathrm{empty}$ lacunae; $\mathrm{Ot}=\mathrm{osteocyte}$ with visible nuclei; Ap.Ot=apoptotic osteocyte; $\mathrm{T}(-) . \mathrm{Ot}=\mathrm{TUNEL}$ negative osteocyte, $\mathrm{L} . \mathrm{Pm}=$ labeled perimeter; $\mathrm{B} . \mathrm{Pm}=$ bone perimeter; surface $\mathrm{MAR}=$ surface mineral apposition rate; Ia.Ct.MAR = intracortical MAR, $\mathrm{BFR}=$ bone formation rate; $\mathrm{Po}=$ porosity; $\mathrm{W} . \mathrm{Wi}=$ wall width; On= complete secondary osteon; FOn=filling osteon; Rs $=$ resorption cavity, Ac.f $=$ activation frequency. 
Table 6

Simple linear regressions for modeling parameters

\begin{tabular}{|c|c|c|c|c|}
\hline$x$ & $y$ & Regression & $R^{2}$ & $p$-value \\
\hline \multirow[t]{2}{*}{ e.Lc.Dn $\left(\# / \mathrm{mm}^{2}\right)$} & Forming surface, $\%$ & L.Pm/B.Pm $=0.34 x-15.57$ & 0.876 & 0.0006 \\
\hline & Surface mineral apposition rate, $\mu \mathrm{m} /$ day & Surface MAR $=-0.015 x+4.61$ & 0.590 & 0.0259 \\
\hline e.Lc.N, \# & Forming surface, $\%$ & L.Pm/B.Pm $=2.93 x-27.91$ & 0.825 & 0.0018 \\
\hline Lc.N, \# & Surface mineral apposition rate, $\mu \mathrm{m} /$ day & Surface MAR $=-0.15 x+5.55$ & 0.721 & 0.0077 \\
\hline \multirow[t]{2}{*}{ Ap.Ot.Dn (\#/mm²) } & Forming surface, $\%$ & L.Pm/B.Pm $=-0.3 x+50.78$ & 0.206 & 0.4474 \\
\hline & Surface mineral apposition rate, $\mu \mathrm{m} /$ day & Surface MAR $=0.02 x+1.29$ & 0.392 & 0.9384 \\
\hline Porosity, $\%$ & Bone formation rate, $\mu \mathrm{m}^{2} /$ day $/ \mu \mathrm{m}$ & $\mathrm{BFR} / \mathrm{BS}=-1.05 x+4.39$ & 0.595 & 0.0251 \\
\hline
\end{tabular}

parameters in animals that, like humans, undergo normal intracortical remodeling.

Although the correlation between BMU activation frequency and the density of apoptotic osteocytes in this study was best described by a linear relationship, as compared to a power law or exponential fit, the data suggest that there was a threshold density beyond which increases in both apoptotic osteocytes and remodeling coincided (Fig. 3). Below a density of approximately 45 apoptotic osteocytes $/ \mathrm{mm}^{2}$, there appeared to be a baseline remodeling level that was relatively constant and not dependent on the density of osteocytes undergoing apoptosis (Ac.f $=5.4 \mathrm{BMUs} / \mathrm{mm}^{2} /$ year). Above this threshold of 45 apoptotic osteocytes $/ \mathrm{mm}^{2}$, activation frequency increased in a linear fashion; and the correlation between activation frequency and apoptotic osteocyte density was very strong and statistically significant (Ac. $\mathrm{f}=1.57 x-63.835, R^{2}=0.829$, $p=0.0017)$.

In addition to the spatial correlations, we found the rabbit tibial midshaft to be characterized by statistically significant regional variability in indices of remodeling, modeling, osteocyte and lacunar density, empty lacunar density, and apoptotic osteocyte density. Variability in remodeling was found to follow a regular pattern of reduced activity in cranial quadrants and pericortical subregions. Formative modeling parameters were also found to follow a regular pattern with differences most pronounced between periosteal and endosteal surfaces, where it was observed that the periosteal surface of each quadrant demonstrated a greater amount of bone forming surface, but at a concomitantly reduced bone mineralization rate, compared to the endosteal surface.

Previous experimental studies have demonstrated that viable osteocytes exhibit an inhibitory effect on bone remodeling and formation processes. In a cultured organ system, Gu et al. [32] found that osteocyte death stops the inhibition of osteoclasts, triggering local bone resorption. Earlier work by Qiu et al. [71] showed a weak but significant negative correlation between osteocyte density and bone formation rate in transiliac bone biopsies from pre- and post-menopausal, but skeletally healthy, women. Metz et al. [58] also demonstrated a statistically significant, but weak, negative correlation between osteocyte lacunar density and normalized intracortical mineral apposition rate. These studies support the theory that osteocytes inhibit bone turnover processes in general, and bone formation in particular.
In contrast, other studies have found increased osteocyte and lacunar densities in association with younger, more recently remodeled bone. Power et al. [67] demonstrated elevated levels of lacunar occupancy and osteocyte density in bone surrounding forming and resorbing osteons compared with quiescent surfaces in human femoral neck biopsies. Earlier work by Vashishth et al. [91] showed an age-related decline in lacunar density that was correlated with microcrack accumulation in human femoral mid-diaphyses. More recent work by Qiu et al. [69] has confirmed that osteocyte deficits occur in concert with increased microdamage, but not necessarily animal age. Skedros et al. [79] also recently have shown a positive, but weak, correlation between lacunar density and new remodeling events (i.e. resorbing and forming osteons) in mule deer calcanei. Taken together, these studies reinforce the notion that osteocytes actively initiate and control bone resorption and subsequent remodeling.

Several recent studies have called into question whether population densities of osteocyte lacunae truly correlate with modeling or remodeling parameters. Looking at functional adaptation to externally applied loads on mice ulnae from three different inbred strains, Robling and Turner [72] showed that bone size and osteocyte lacunar density were not related to mechanosensitivity as measured by periosteal bone formation. Da Costa Gomez et al. [16] corroborated this finding in a histologic study on equine third metacarpal bones, showing no significant relationships between osteocyte lacunar density and indices of remodeling (Ac.f, Rs.N/T.Ar), modeling (BFR), bone volume fraction, and the lengths and densities of microcracks. These authors concluded that site-specific induction of remodeling during functional adaptation of bone in high strain skeletal sites is not dependent on the accumulation of microcracks or loss of osteocytes [16]. The lack of a clear functional association between lacunar density and measures of bone turnover also was confirmed recently by Skedros et al. [78]. In mid-third diaphyseal equine radii and third metacarpals from skeletally mature animals, the investigators tested several hypotheses correlating population densities of osteocyte lacunae with structural and material characteristics of bone, strain modes, microdamage, and remodeling parameters. In contrast with their earlier study [79], they found relatively uniform lacunar densities in regions characterized by highly non-uniform strains and heterogeneous structural organization, suggesting that population densities of osteocytes were poorly correlated with 
mechanobiological characteristics [78]. Instead, Skedros et al. [78] suggested that osteocyte densities may be strongly influenced by other factors, in particular regional rates of bone formation. Assuming that a fixed proportion of osteoblasts differentiate to osteocytes during the formation process, they reasoned that osteocyte densities would be proportional to bone formation rates. This belief was not confirmed by our study, which did not find significant relationships between lacunar or osteocyte densities and intracortical or surface bone formation rates. Our results, however, could be influenced by the recent finding that osteocytes participate in a regulatory mechanism that inhibits bone formation $[58,71]$. That is, while it may be plausible that osteocyte cell populations are governed by apposition rates during modeling and remodeling, they also exhibit feedback control on the amount of bone formed, confounding the relationships between these parameters.

The uncertainties surrounding correlations of lacunar density with modeling and remodeling indices have given the study of osteocyte viability renewed importance. In this regard, several recent studies have confirmed that osteocyte apoptosis occurs in vivo under a variety of conditions normally associated with bone turnover, including distraction osteogenesis [50], estrogen withdrawal [88,89], glucocorticoid administration [21,31,96], removal of normal mechanical load [1], and in association with fatigue microdamage caused by externally applied supraphysiologic loads $[5,62,92,93]$. These latter experiments have demonstrated that osteocyte apoptosis is typically not systemic but highly localized to sites of microdamage that are subsequently remodeled $[5,62,92,93]$.

We believe that the results presented here help resolve some of the current controversy in osteocyte function. Specifically, our finding that osteocyte apoptosis correlates directly with intracortical remodeling supports both the hypothesis that osteocyte networks inhibit an otherwise basal remodeling response (such that their programmed death removes this natural inhibition) and the theory that apoptotic osteocytes produce a signal that initiates and guides osteoclastic resorption of bone. However, our finding of a negative correlation between empty lacunar density and intracortical remodeling reinforces only the latter theory. If the absence of intact, functional osteocyte networks initiates remodeling as suggested by the theory of remodeling inhibition, then the "emptying" of lacunae would suffice as a process initiator. Experimentally, however, we found the opposite correlation. On the other hand, the latter theory, which implies that increasing numbers of empty lacunae mean that fewer "viable" osteocytes are available to die via programmed cell death, decreasing the potential signal for osteoclastic resorption and thus the remodeling response, is supported by our findings.

How then should we interpret empty lacunae? While it has been suggested that routine histologic preparation shrinks and distorts osteocytes [73,97], the correlations we found between empty lacunae, modeling, and remodeling suggest that they are more than just artifacts of tissue processing and sectioning. Rather, despite their characterization as long-lived cells, it has been well known for decades that osteocytes die in vivo. Frost [24] first recognized an age-related decline in osteocyte density that was more pronounced than similar declines in lacunar density. Several investigations over the past decade have shown convincing evidence that osteocytes die by apoptosis $[63,89,92]$. Boyce et al. [8] elaborate on the histological consequences of this process by noting that, during the last stages of programmed cell death, osteocytes break up into apoptotic bodies that may be less than $2-3 \mu \mathrm{m}$ in diameter. Such bodies are likely to remain undetectable to light microscopy and may well be interpreted as empty lacunae. The authors go on to suggest that, if large numbers of osteocytes are undergoing apoptosis at the time of tissue harvest, it is likely that many other osteocytes underwent apoptosis previously, becoming shrunken and fragmented and disappearing from their lacunae. Thus, large numbers of presently apoptotic cells should be found in conjunction with elevated levels of fragmented or absent osteocytes (i.e. empty lacunae) [8]. Though the first part of this hypothesis is plausible, the second is not consistent with our data, in that empty lacunae and apoptotic osteocytes were not correlated, nor did they share consistent relationships with indices of either remodeling or modeling. However, empty lacunae may represent osteocytes that previously died by apoptosis, secreted a remodeling signal, shrunk into undetectable apoptotic bodies, and then were preferentially removed by tunneling BMUs, thereby accounting for the negative correlation with remodeling indices. Indeed, recent investigations utilizing electron and light microscopy demonstrate both osteoclastic engulfment of apoptotic osteocytes and osteoclastic release of viable osteocytes from their lacunae $[6,85,86]$. Alternatively, the presence of empty lacunae in our study may be explained by mechanisms other than apoptosis that lead to cell death, namely necrosis or autophagy $[22,42,49]$, a process by which cells degrade their own organelles to produce energy as a survival mechanism during periods of nutrient stress. Although cells from various tissues in a diverse range of species have been shown to undergo autophagy, this process has not yet been demonstrated experimentally in osteocytes.

An examination of the effects that osteocytes have on bone formation may shed light on the relationship between empty lacunae and modeling. It is well known that lacunar occupancy decreases with age; that is, empty lacunar density increases past skeletal maturity $[68,70]$. This increase is paralleled by an increase in periosteal bone apposition, at least in individuals who are not estrogen-suppressed such as post-menopausal women $[47,48,53,75,76]$. These two phenomena may be linked. Previous work by Qiu et al. [71] and Metz et al. [58] demonstrate that osteocytes exert an inhibitory effect on bone formation. It has also been shown recently that osteocytes secrete sclerostin, a potent BMP antagonist that inhibits bone formation $[4,66]$. Taken together, these findings suggest a model in which intact osteocyte networks inhibit bone formation and that the "emptying" of lacunae, which would remove this inhibitory effect of sclerostin, permits apposition to occur in response to normal loading. Still, this does not explain the negative correlation found in our study between empty lacunae and surface mineral apposition rate, which also was negatively correlated with the amount of active mineralization. To date, the effects of sclerostin on the amounts and rates of periosteal and endosteal bone formation are poorly understood, and continued research is necessary to understand 
the underlying mechanisms leading to the observed relationships between osteocytes, empty lacunae, and modeling.

Several limiting assumptions have been made in the present investigation. It was assumed, for example, that surface modeling activity was not related to longitudinal bone growth because the rabbits were skeletally mature and did not have active growth plates. A previous study of cortical bone in skeletally mature rabbits demonstrated considerable bone formation in tibial midshafts under normal loading conditions [55]. In addition, microdamage was not included in the linear regression models or statistical correlations. A total of seven microcracks, as measured by standard basic fuchsin staining, were found in two of the eight experimental animals. Although all microcracks were detected in caudal and medial quadrants, which were also characterized by elevated levels of remodeling, they were not included in the analysis because of the relatively few specimens that exhibited cracks. A further limitation was the use of histologic sections from contralateral limbs for histomorphometry and TUNEL, based on the supposition that left and right tibiae were indistinguishable in their loading environment and general microstructure. Despite this assumption, apoptotic osteocytes were found to correlate strongly with remodeling parameters, as did empty lacunae with formative modeling parameters. These relationships could be stronger in specimens taken from the same limb.

There were also limitations inherent in the technique used to detect apoptotic osteocytes. TUNEL, which detects apoptotic cells by marking double-stranded breaks in DNA, is subject to false-positive staining and a lack of specificity [8]. Artificial DNA breaks may be caused by histological processing, such as inadequate fixation, sectioning, drying out during staining, and the effect of proteases $[36,43,82,87]$. Each group of bone sections, however, received the same processing and staining regimens, such that relative differences between sites in a crosssection can be assumed to have been conserved. TUNEL also may label non-apoptotic osteocytes characterized by DNA breaks due to necrosis, DNA repair mechanisms, and DNA translation $[41,94]$. To minimize the effects of such non-specific labeling, methyl green, a counterstain that preferentially labels acidic nuclei, was used in the TUNEL analysis to identify nonapoptotic osteocytes, classical morphological features of those cells undergoing apoptosis were detected in osteocytes believed to be undergoing apoptosis, and a subset of TUNEL-positive osteocytes were categorized as apoptotic. That said, the average percentage of apoptotic osteocytes among all quadrants and regions in tibial midshafts of skeletally mature rabbits was approximately $9 \%$. Although this value is higher than that previously reported in mice [1], it is statistically similar to previous findings in humans and rats $[62,89,92]$. It should be noted, though, that the relative differences between our study and others on mice and rats may be because those animals, unlike rabbits, do not undergo normal intracortical remodeling in the absence of pathology or external stimuli.

In conclusion, this study presents the first quantitative evidence of a strong, linear, spatial correlation between osteocyte apoptosis and intracortical remodeling in the rabbit tibial midshaft. It also demonstrates a linear correlation between empty lacunae and indices of formative modeling, corroborating previous studies that have found the osteocytic network to inhibit bone formation processes. It is noteworthy that the densities of total lacunae and total osteocytes did not significantly correlate with modeling or remodeling parameters, suggesting that an examination of cell viability is necessary in studies correlating bone turnover parameters with the functional role of osteocytes in bone adaptation. The correlations found in our study support the belief that the osteocyte-canalicular network is involved in the mechanosensory mechanism that activates bone remodeling and that osteocytes undergoing apoptosis produce signals that attract or direct osteoclastic resorption in the remodeling process.

\section{Acknowledgments}

This work was supported by Whitaker Foundation grant RG02-0630.

\section{References}

[1] Aguirre JI, Plotkin LI, Stewart SA, Weinstein RS, Parfitt AM, Manolagas $\mathrm{SC}$, et al. Osteocyte apoptosis is induced by weightlessness in mice and precedes osteoclast recruitment and bone loss. J Bone Miner Res 2006; 21:605-15.

[2] Ausk BJ, Gross TS, Srinivasan S. An agent based model for real-time signaling induced in osteocytic networks by mechanical stimuli. J Biomech 2006;39:2638-46.

[3] Belanger LF. Osteocytic osteolysis. Calcif Tissue Res 1969;4:1-12.

[4] Bellido T, Ali AA, Gubrij I, Plotkin LI, Fu Q, O’Brien CA, et al. Chronic elevation of parathyroid hormone in mice reduces expression of sclerostin by osteocytes: a novel mechanism for hormonal control of osteoblastogenesis. Endocrinology 2005;146:4577-83.

[5] Bentolila V, Boyce TM, Fyhrie DP, Drumb R, Skerry TM, Schaffler MB. Intracortical remodeling in adult rat long bones after fatigue loading. Bone 1998;23:275-81.

[6] Boabaid F, Cerri PS, Katchburian E. Apoptotic bone cells may be engulfed by osteoclasts during alveolar bone resorption in young rats. Tissue Cell 2001;33:318-25.

[7] Bonewald LF. Osteocyte biology. Curr Opin Orthop 2003;14:311-6.

[8] Boyce BF, Hughes DE, Wright KR. Methods for studying cell death in bone. In: Arnett TR, Henderson B, editors. Methods in bone biology. London: Chapman and Hall; 1998. p. 128-48.

[9] Bronckers AL, Goei W, Luo G, Karsenty G, D'Souza RN, Lyaruu DM, et al. DNA fragmentation during bone formation in neonatal rodents assessed by transferase-mediated end labeling. J Bone Miner Res 1996; 11:1281-91.

[10] Burger EH, Klein-Nulend J. Mechanotransduction in bone-role of the lacuno-canalicular network. FASEB J 1999;13:S101-12 [Suppl.].

[11] Burger EH, Klein-Nulend J, Smit TH. Strain-derived canalicular fluid flow regulates osteoclast activity in a remodelling osteon-a proposal. J Biomech 2003;36:1453-9.

[12] Burr DB, Martin RB. Calculating the probability that microcracks initiate resorption spaces. J Biomech 1993;26:613-6.

[13] Burr DB, Stafford T. Validity of the bulk-staining technique to separate artifactual from in vivo bone microdamage. Clin Orthop Relat Res 1990;260:305-8.

[14] Cowin SC, Weinbaum S, Zeng Y. A case for bone canaliculi as the anatomical site of strain generated potentials. J Biomech 1995;28: 1281-1297.

[15] Cullinane DM. The role of osteocytes in bone regulation: mineral homeostasis versus mechanoreception. J Musculoskelet Neuronal Interact 2002;2:242-4

[16] Da Costa Gomez TM, Barrett JG, Sample SJ, Radtke CL, Kalscheur VL, Lu Y, et al. Up-regulation of site-specific remodeling without accumulation of microcracking and loss of osteocytes. Bone 2005;37:16-24. 
[17] Dodd JS, Raleigh JA, Gross TS. Osteocyte hypoxia: a novel mechanotransduction pathway. Am J Physiol: Cell Physiol 1999;277:C598-602.

[18] Doty SB. Morphological evidence of gap junctions between bone cells. Calcif Tissue Int 1981;33:509-12.

[19] Duncan R, Misler S. Voltage-activated and stretch-activated Ba2+ conducting channels in an osteoblast-like cell line (UMR 106). FEBS Lett 1989;251:17-21.

[20] Duncan RL, Turner CH. Mechanotransduction and the functional response of bone to mechanical strain. Calcif Tissue Int 1995;57:344-58.

[21] Eberhardt AW, Yeager-Jones A, Blair HC. Regional trabecular bone matrix degeneration and osteocyte death in femora of glucocorticoidtreated rabbits. Endocrinology 2001;142:1333-40.

[22] Edinger AL, Thompson CB. Death by design: apoptosis, necrosis and autophagy. Curr Opin Cell Biol 2004;16:663-9.

[23] Feik SA, Thomas CD, Bruns R, Clement JG. Regional variations in cortical modeling in the femoral mid-shaft: sex and age differences. Am J Phys Anthropol 2000;112:191-205.

[24] Frost HM. In vivo osteocyte death. J Bone Jt Surg Am 1960;42-A: 138-43.

[25] Frost HM. Bone histomorphometry: correction of the labeling "escape error”. In: Recker RR, editor. Bone histomorphometry: techniques and interpretations. Boca Raton: CRC Press; 1983. p. 133-42.

[26] Gibson VA, Stover SM, Gibeling JC, Hazelwood SJ, Martin RB. Osteonal effects on elastic modulus and fatigue life in equine bone. $\mathrm{J}$ Biomech 2006;39:217-25.

[27] Gross TS, Akeno N, Clemens TL, Komarova S, Srinivasan S, Weimer DA, et al. Selected contribution: osteocytes upregulate HIF-1alpha in response to acute disuse and oxygen deprivation. J Appl Physiol 2001;90:2514-9.

[28] Gross TS, Edwards JL, McLeod KJ, Rubin CT. Strain gradients correlate with sites of periosteal bone formation. J Bone Miner Res 1997;12: 982-8.

[29] Gross TS, King KA, Rabaia NA, Pathare P, Srinivasan S. Upregulation of osteopontin by osteocytes deprived of mechanical loading or oxygen. J Bone Miner Res 2005;20:250-6.

[30] Gross TS, Poliachik SL, Ausk BJ, Sanford DA, Becker BA, Srinivasan S. Why rest stimulates bone formation: a hypothesis based on complex adaptive phenomenon. Exerc Sport Sci Rev 2004;32:9-13.

[31] Gu G, Hentunen TA, Nars M, Harkonen PL, Vaananen HK. Estrogen protects primary osteocytes against glucocorticoid-induced apoptosis. Apoptosis 2005;10:583-95.

[32] Gu G, Mulari M, Peng Z, Hentunen TA, Vaananen HK. Death of osteocytes turns off the inhibition of osteoclasts and triggers local bone resorption. Biochem Biophys Res Commun 2005;335:1095-101.

[33] Han Y, Cowin SC, Schaffler MB, Weinbaum S. Mechanotransduction and strain amplification in osteocyte cell processes. Proc Natl Acad Sci 2004;101:16689-94

[34] Harrigan TP, Hamilton JJ. Bone strain sensation via transmembrane potential changes in surface osteoblasts: loading rate and microstructural implications. J Biomech 1993;26:183-200.

[35] Iwaniec UT, Crenshaw TD. Distribution of mineralization indices of modeling and remodeling over eight months in middiaphyseal cross sections of femurs from adult swine. Anat Rec 1998;250:136-45.

[36] Jerome KR, Vallan C, Jaggi R. The TUNEL assay in the diagnosis of graft-versus-host disease: caveats for interpretation. Pathology 2000; 32:186-90.

[37] Jones SJ, Gray C, Sakamaki H, Arora M, Boyde A, Gourdie R, et al. The incidence and size of gap junctions between the bone cells in rat calvaria. Anat Embryol 1993;187:343-52.

[38] Judex S, Gross TS, Zernicke RF. Strain gradients correlate with sites of exercise-induced bone-forming surfaces in the adult skeleton. J Bone Miner Res 1997;12:1737-45.

[39] Kimmel DB. A paradigm for skeletal strength homeostasis. J Bone Miner Res 1993;8(Suppl 2):S515-22.

[40] Kimmel DB, Jee WSS. Measurements of area, perimeter, and distance: details of data collection in bone histomorphometry. In: Recker RR, editor. Bone histomorphometry: techniques and interpretations. Boca Raton: CRC Press; 1983. p. 89-108.
[41] Kockx MM, Muhring J, Knaapen MW, de Meyer GR. RNA synthesis and splicing interferes with DNA in situ end labeling techniques used to detect apoptosis. Am J Pathol 1998;152:885-8.

[42] Kundu M, Thompson CB. Macroautophagy versus mitochondrial autophagy: a question of fate? Cell Death Differ 2005;12(Suppl 2): 1484-9.

[43] Labat-Moleur F, Guillermet C, Lorimier P, Robert C, Lantuejoul S, Brambilla E, et al. TUNEL apoptotic cell detection in tissue sections: critical evaluation and improvement. J Histochem Cytochem 1998; 46:327-34.

[44] Lane NE, Yao W, Balooch M, Nalla RK, Balooch G, Habelitz S, et al. Glucocorticoid-treated mice have localized changes in trabecular bone material properties and osteocyte lacunar size that are not observed in placebo-treated or estrogen-deficient mice. J Bone Miner Res 2006; 21:466-76.

[45] Lanyon LE. Functional strain in bone tissue as an objective, and controlling stimulus for adaptive bone remodelling. J Biomech 1987;20: 1083-93.

[46] Lanyon LE. Osteocytes, strain detection, bone modeling and remodeling. Calcif Tissue Int 1993;53(Suppl 1):S102-6.

[47] Lazenby RA. Continuing periosteal apposition. I: Documentation, hypotheses, and interpretation. Am J Phys Anthropol 1990;82:451-72.

[48] Lazenby RA. Continuing periosteal apposition. II: The significance of peak bone mass, strain equilibrium, and age-related activity differentials for mechanical compensation in human tubular bones. Am J Phys Anthropol 1990;82:473-84.

[49] Levine B, Yuan J. Autophagy in cell death: an innocent convict? J Clin Invest 2005;115:2679-88.

[50] Li G, Dickson GR, Marsh DR, Simpson H. Rapid new bone tissue remodeling during distraction osteogenesis is associated with apoptosis. J Orthop Res 2003;21:28-35.

[51] Marotti G, Cane V, Palazzini S, Palumbo C. Structure-function relationships in the osteocyte. Ital J Min Electrolyte Metab 1990;4: 93-106.

[52] Martin RB. Toward a unifying theory of bone remodeling. Bone 2000; 26:1-6.

[53] Martin RB, Burr DB, Sharkey NA. Skeletal Tissue Mechanics. New York: Springer; 1998. p. 134-43.

[54] Martin RB, Stover SM, Gibson VA, Gibeling JC, Griffin LV. In vitro fatigue behavior of the equine third metacarpus: remodeling and microcrack damage analysis. J Orthop Res 1996;14:794-801.

[55] Mashiba T, Burr DB, Turner CH, Sato M, Cain RL, Hock JM. Effects of human parathyroid hormone (1-34), LY333334, on bone mass, remodeling, and mechanical properties of cortical bone during the first remodeling cycle in rabbits. Bone 2001;28:538-47.

[56] Mason DJ, Hillam RA, Skerry TM. Constitutive in vivo mRNA expression by osteocytes of beta-actin, osteocalcin, connexin-43, IGF-I, c-fos and c-jun, but not TNF-alpha nor tartrate-resistant acid phosphatase. J Bone Miner Res 1996;11:350-7.

[57] Menton DN, Simmons DJ, Chang SL, Orr BY. From bone lining cell to osteocyte - an SEM study. Anat Rec 1984;209:29-39.

[58] Metz LN, Martin RB, Turner AS. Histomorphometric analysis of the effects of osteocyte density on osteonal morphology and remodeling. Bone 2003;33:753-9.

[59] Mori S, Burr DB. Increased intracortical remodeling following fatigue damage. Bone 1993;14:103-9.

[60] Mullender MG, Huiskes R. Proposal for the regulatory mechanism of Wolff's law. J Orthop Res 1995;13:503-12.

[61] Nicolella DP, Moravits DE, Gale AM, Bonewald LF, Lankford J. Osteocyte lacunae tissue strain in cortical bone. J Biomech 2006;39: 1735-43.

[62] Noble BS, Peet N, Stevens HY, Brabbs A, Mosley JR, Reilly GC, et al. Mechanical loading: biphasic osteocyte survival and targeting of osteoclasts for bone destruction in rat cortical bone. Am J Physiol: Cell Physiol 2003;284:C934-43.

[63] Noble BS, Stevens H, Loveridge N, Reeve J. Identification of apoptotic changes in osteocytes in normal and pathological human bone. Bone 1997;20:273-82. 
[64] Palumbo C, Palazzini S, Marotti G. Morphological study of intercellular junctions during osteocyte differentiation. Bone 1990;11:401-6.

[65] Pienkowski D, Pollack SR. The origin of stress-generated potentials in fluid-saturated bone. J Orthop Res 1983;1:30-41.

[66] Poole KE, van Bezooijen RL, Loveridge N, Hamersma H, Papapoulos $\mathrm{SE}$, Lowik CW, et al. Sclerostin is a delayed secreted product of osteocytes that inhibits bone formation. FASEB J 2005;19:1842-4.

[67] Power J, Loveridge N, Rushton N, Parker M, Reeve J. Osteocyte density in aging subjects is enhanced in bone adjacent to remodeling haversian systems. Bone 2002;30:859-65.

[68] Power J, Noble BS, Loveridge N, Bell KL, Rushton N, Reeve J. Osteocyte lacunar occupancy in the femoral neck cortex: an association with cortical remodeling in hip fracture cases and controls. Calcif Tissue Int 2001;69:13-9.

[69] Qiu S, Rao DS, Fyhrie DP, Palnitkar S, Parfitt AM. The morphological association between microcracks and osteocyte lacunae in human cortical bone. Bone 2005;37:10-5.

[70] Qiu S, Rao DS, Palnitkar S, Parfitt AM. Age and distance from the surface but not menopause reduce osteocyte density in human cancellous bone. Bone 2002;31:313-8.

[71] Qiu S, Rao DS, Palnitkar S, Parfitt AM. Relationships between osteocyte density and bone formation rate in human cancellous bone. Bone 2002;31:709-11.

[72] Robling AG, Turner $\mathrm{CH}$. Mechanotransduction in bone: genetic effects on mechanosensitivity in mice. Bone 2002;31:562-9.

[73] Ross MH, Kaye GI, Pawlina W. Histology: a text and atlas. Philadelphia: Lippincott Williams and Wilkins; 2003. p. 180-213.

[74] Rubin CT, Lanyon LE. Regulation of bone mass by mechanical strain magnitude. Calcif Tissue Int 1985;37:411-7.

[75] Russo CR, Lauretani F, Seeman E, Bartali B, Bandinelli S, Di Iorio A, et al. Structural adaptations to bone loss in aging men and women. Bone 2006;38:112-8.

[76] Seeman E. During aging, men lose less bone than women because they gain more periosteal bone, not because they resorb less endosteal bone. Calcif Tissue Int 2001;69:205-8.

[77] Shea JF, Yeager VL, Taylor JJ. Bone resorption by osteocytes. Proc Soc Exp Biol Med 1968;129:41-3.

[78] Skedros JG, Grunander TR, Hamrick MW. Spatial distribution of osteocyte lacunae in equine radii and third metacarpals: considerations for cellular communication, microdamage detection and metabolism. Cells Tissues Organs 2005;180:215-36.

[79] Skedros JG, Hunt KJ, Bloebaum RD. Relationships of loading history and structural and material characteristics of bone: development of the mule deer calcaneus. J Morphol 2004;259:281-307.

[80] Skerry TM, Bitensky L, Chayen J, Lanyon LE. Early strain-related changes in enzyme activity in osteocytes following bone loading in vivo. J Bone Miner Res 1989;4:783-8.

[81] Skinner RA, Hickmon SG, Lumpkin CK, Aronson J, Nicholas RW. Decalcified bone: twenty years of successful specimen management. J Histotechnol 1997;20:267-77.

[82] Sloop GD, Roa JC, Delgado AG, Balart JT, Hines III MO, Hill JM. Histologic sectioning produces TUNEL reactivity. A potential cause of false-positive staining. Arch Pathol Lab Med 1999;123:529-32.
[83] Smit TH, Burger EH, Huyghe JM. A case for strain-induced fluid flow as a regulator of BMU-coupling and osteonal alignment. J Bone Miner Res 2002;17:2021-9.

[84] Stains JP, Civitelli R. Cell-to-cell interactions in bone. Biochem Biophys Res Commun 2005;328:721-7.

[85] Suzuki R, Domon T, Wakita M. Some osteocytes released from their lacunae are embedded again in the bone and not engulfed by osteoclasts during bone remodeling. Anat Embryol 2000;202:119-28.

[86] Suzuki R, Domon T, Wakita M, Akisaka T. The reaction of osteoclasts when releasing osteocytes from osteocytic lacunae in the bone during bone modeling. Tissue Cell 2003;35:189-97.

[87] Tateyama H, Tada T, Hattori H, Murase T, Li WX, Eimoto T. Effects of prefixation and fixation times on apoptosis detection by in situ endlabeling of fragmented DNA. Arch Pathol Lab Med 1998;122:252-5.

[88] Tomkinson A, Gevers EF, Wit JM, Reeve J, Noble BS. The role of estrogen in the control of rat osteocyte apoptosis. J Bone Miner Res 1998; 13:1243-50.

[89] Tomkinson A, Reeve J, Shaw RW, Noble BS. The death of osteocytes via apoptosis accompanies estrogen withdrawal in human bone. J Clin Endocrinol Metab 1997;82:3128-35.

[90] Torrance AG, Mosley JR, Suswillo RF, Lanyon LE. Noninvasive loading of the rat ulna in vivo induces a strain-related modeling response uncomplicated by trauma or periosteal pressure. Calcif Tissue Int 1994;54:241-7.

[91] Vashishth D, Verborgt O, Divine G, Schaffler MB, Fyhrie DP. Decline in osteocyte lacunar density in human cortical bone is associated with accumulation of microcracks with age. Bone 2000;26:375-80.

[92] Verborgt O, Gibson GJ, Schaffler MB. Loss of osteocyte integrity in association with microdamage and bone remodeling after fatigue in vivo. J Bone Miner Res 2000;15:60-7.

[93] Verborgt O, Tatton NA, Majeska RJ, Schaffler MB. Spatial distribution of Bax and Bcl-2 in osteocytes after bone fatigue: complementary roles in bone remodeling regulation? J Bone Miner Res 2002;17:907-14.

[94] Watanabe M, Hitomi M, van der Wee K, Rothenberg F, Fisher SA, Zucker $\mathrm{R}$, et al. The pros and cons of apoptosis assays for use in the study of cells, tissues, and organs. Microsc Microanal 2002;8:375-91.

[95] Weinbaum S, Cowin SC, Zeng Y. A model for the excitation of osteocytes by mechanical loading-induced bone fluid shear stresses. J Biomech 1994;27:339-60.

[96] Weinstein RS, Nicholas RW, Manolagas SC. Apoptosis of osteocytes in glucocorticoid-induced osteonecrosis of the hip. J Clin Endocrinol Metab 2000;85:2907-12.

[97] Wheater PR, Burkitt HG, Daniels VG. Functional histology: a text and colour atlas. Edinburgh: Churchill Livingstone; 1987. p. 142-60.

[98] Yellowley CE, Li Z, Zhou Z, Jacobs CR, Donahue HJ. Functional gap junctions between osteocytic and osteoblastic cells. J Bone Miner Res 2000;15:209-17.

[99] You J, Yellowley CE, Donahue HJ, Zhang Y, Chen Q, Jacobs CR. Substrate deformation levels associated with routine physical activity are less stimulatory to bone cells relative to loading-induced oscillatory fluid flow. J Biomech Eng 2000;122:387-93.

[100] You L, Cowin SC, Schaffler MB, Weinbaum S. A model for strain amplification in the actin cytoskeleton of osteocytes due to fluid drag on pericellular matrix. J Biomech 2001;34:1375-86. 